\title{
ТЕНДЕНЦИИ ЗЕМЛЕПОЛЬЗОВАНИЯ В РОССИИ
}

\author{
Мазуркин П.М. \\ Поволжский государственный технологический университет, \\ Йошкар-Ола, Россия.
}

Введение. Изменения в земельном кадастре субъектов Федерации учитывались три раза: вначале был период 1985-1999 гг. [2, 4], второй раз 1985-2005 гг. $[8,9]$. В статье [5] дается третья итерация по динамическому ряду 1985-2012 гг. Методология факторного анализа изложена в [1, 3, 6-10].

Цель статьи - показать метод анализа динамики площади сельскохозяйственных угодий и её подкатегорий.

Исходные данные. По данным за 2011 год [11] (табл. 1) дополнительно были введены удельные показатели: доли пашни, сенокосов и пастбищ, залежей по отношению к сельхозугодиям.

\section{Таблица Ошибка! Текст указанного стиля в документе отсутствует.}

Динамика площади сельскохозяйственных угодий Российской Федерации с 1990 по 2011 годы (с землями личного пользования)

\begin{tabular}{|c|c|c|c|c|c|c|c|c|}
\hline \multirow[b]{2}{*}{ Год } & \multirow[b]{2}{*}{$\begin{array}{r}\text { Время } \\
t, \text { лет }\end{array}$} & \multirow{2}{*}{$\begin{array}{c}\text { Сельско- } \\
\text { хозяйственные } \\
\text { угодья } S_{C X У}\end{array}$} & \multicolumn{3}{|c|}{ в том числе, тыс. га } & \multicolumn{3}{|c|}{ Доля в СХУ, \% } \\
\hline & & & $\begin{array}{c}\text { пашня } \\
S_{\Pi}\end{array}$ & $\mid \begin{array}{c}\text { сенокосы } \\
\text { и пастб. } S_{C \Pi} \mid\end{array}$ & $\begin{array}{c}\text { залежь } \\
S_{3}\end{array}$ & $\begin{array}{c}\text { пашня } \\
\alpha_{\Pi}\end{array}$ & $\begin{array}{c}\text { сенокосы } \\
\text { и пастб. } \alpha_{C п}\end{array}$ & $\begin{array}{c}\text { залежь } \\
\alpha_{3}\end{array}$ \\
\hline 1990 & 0 & 222409.2 & 132304.2 & 87899.5 & 347.2 & 59.49 & 39.52 & 0.16 \\
\hline 1991 & 1 & 222407.9 & 132068.7 & 86860.2 & 374.7 & 59.38 & 39.05 & 0.17 \\
\hline 1992 & 2 & 222486.3 & 132004.6 & 88081.1 & 393.4 & 59.33 & 39.59 & 0.18 \\
\hline 1993 & 3 & 222122.0 & 131587.3 & 88248.8 & 481.2 & 59.24 & 39.73 & 0.22 \\
\hline 1994 & 4 & 221794.6 & 130656.2 & 88012.4 & 1097.8 & 58.91 & 39.68 & 0.49 \\
\hline 1995 & 5 & 221985.2 & 130197.6 & 88229.2 & 1456.4 & 58.65 & 39.75 & 0.66 \\
\hline 1996 & 6 & 221634.2 & 128870.9 & 88783.0 & 2003.1 & 58.15 & 40.06 & 0.90 \\
\hline 1997 & 7 & 221491.6 & 127822.8 & 89220.9 & 2501.9 & 57.71 & 40.28 & 1.13 \\
\hline 1998 & 8 & 221161.8 & 126488.6 & 89943.8 & 2874.6 & \begin{tabular}{|l|}
57.19 \\
\end{tabular} & 40.67 & 1.30 \\
\hline 1999 & 9 & 221151.3 & 125331.9 & 90585.6 & 3360.8 & 56.67 & 40.96 & 1.52 \\
\hline 2000 & 10 & 221088.8 & 124373.8 & 90923.4 & 3927.2 & 56.26 & 41.13 & 1.78 \\
\hline 2001 & 11 & 221003.6 & 123859.6 & 91143.0 & 4143.3 & 56.04 & 41.24 & 1.87 \\
\hline 2002 & 12 & 220896.2 & 123464.4 & 91351.4 & 4245.0 & 55.89 & 41.35 & 1.92 \\
\hline 2003 & 13 & 220832.6 & 122558.4 & 91903.6 & 4556.3 & 55.50 & 41.62 & 2.06 \\
\hline 2004 & 14 & 220729.7 & 122146.0 & 92023.7 & 4750.2 & 55.34 & 41.69 & 2.15 \\
\hline 2005 & 15 & 220679.0 & 121780.9 & 92098.8 & 4998.9 & 55.18 & 41.73 & 2.27 \\
\hline 2006 & 16 & 220632.7 & \begin{tabular}{|l|}
121573.9 \\
\end{tabular} & 92117.1 & 5144.3 & 55.10 & 41.75 & 2.33 \\
\hline 2007 & 17 & 220567.9 & 121573.5 & 92094.5 & 5105.7 & 55.12 & 41.75 & 2.31 \\
\hline 2008 & 18 & 220491.6 & 121648.9 & 92052.0 & 4998.0 & 55.17 & 41.75 & 2.27 \\
\hline 2009 & 19 & 220461.6 & 121648.7 & 92053.0 & 4965.2 & 55.18 & 41.75 & 2.25 \\
\hline 2010 & 20 & 220396.3 & 121433.9 & 92059.5 & 5103.3 & 55.10 & 41.77 & 2.32 \\
\hline 2011 & 21 & 220272.1 & 121444.9 & 92028.3 & 4996.9 & 55.13 & 41.78 & 2.27 \\
\hline
\end{tabular}

Далее моделируем динамику шести показателей по трендам.

Динамика СХУ. График на рисунке 1 получает формулу 


$$
\begin{aligned}
& S_{C X Y}=2,22442 \cdot 10^{5} \exp \left(-2,25660 \cdot 10^{-6} t^{2,50550}\right)- \\
& -7,18629 \cdot 10^{5} t^{6,03983} \exp \left(-10,80276 t^{0,27365}\right) .
\end{aligned}
$$

В этом двухчленном тренде первая составляющая является экспоненциальным законом гибели, а вторая кризисным стрессовым возбуждением сельского хозяйства России.

Динамика пашни. Она характеризуется уравнением вида

$$
\begin{gathered}
S_{\Pi}=1,32272 \cdot 10^{5} \exp \left(-0,00093423 t^{1,25704}\right)- \\
-4,97102 \cdot 10^{5} t^{9,98362} \exp \left(-13,04864 t^{0,32361}\right) .
\end{gathered}
$$

Оба уравнения схожи по конструкции.

Тренд получился с двумя членами. При этом конструкция у всех показателей одинаковая: первый член является законом экспоненциальной гибели (отрицательный знак) или роста (положительный знак), а второй - биотехническим законом. При этом второй член вычитается (показывает кризис) или прибавляется. Таким образом, формулы динамики показывают высокую изменчивость параметров земельных ресурсов.

Динамика сенокосов и пастбищ. Она дается формулой

$$
\begin{aligned}
& S_{C I}=87560,916 \exp \left(0,0010613 t^{1,15256}\right)+ \\
& +2,72830 \cdot 10^{6} t^{16,59610} \exp \left(-21,12758 t^{0,33258}\right) .
\end{aligned}
$$
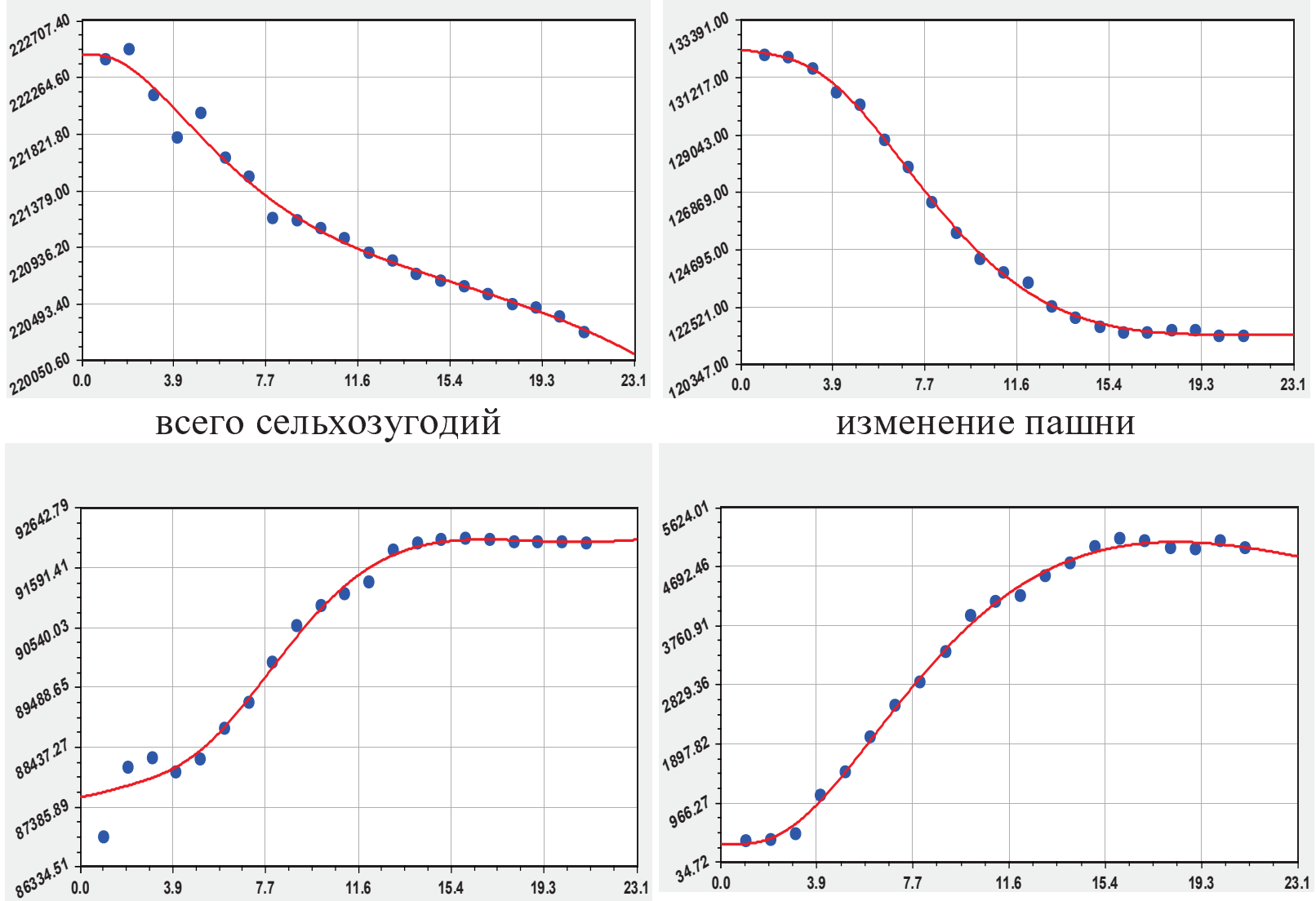

изменение сенокосов и пастбищ изменение залежи

Рис. 1. Графики динамики землепользования с 1990 по 2011 гг. 
Как видно из рисунка 1, с годами происходит снижение площади СХУ и пашни, но сенокосы и пастбища возрастают. При этом их качество по продуктивности травы снижается [6-8].

Динамика залежи. Площадь залежей, то есть отходов полеводства и растениеводства, нарастает по формуле

$$
\begin{aligned}
& S_{3}=317,71667 \exp \left(0,00019861 t^{2,42465}\right)+ \\
& +4,34933 \cdot 10^{7} t^{7,84600} \exp \left(-15,56247 t^{0,24739}\right) .
\end{aligned}
$$

Тенденция получила максимум в 2006 году.

Далее примем площадь СХУ за базовый показатель.

Доля в СХУ пашни. Это отношение меняется (рис. 2) по двухчленной формуле

$$
\begin{gathered}
\alpha_{\Pi}=59,45534 \exp \left(-0,00038310 t^{1,56397}\right)- \\
-0,0033437 t^{4,15524} \exp \left(-0,30174 t^{1,00375}\right) .
\end{gathered}
$$

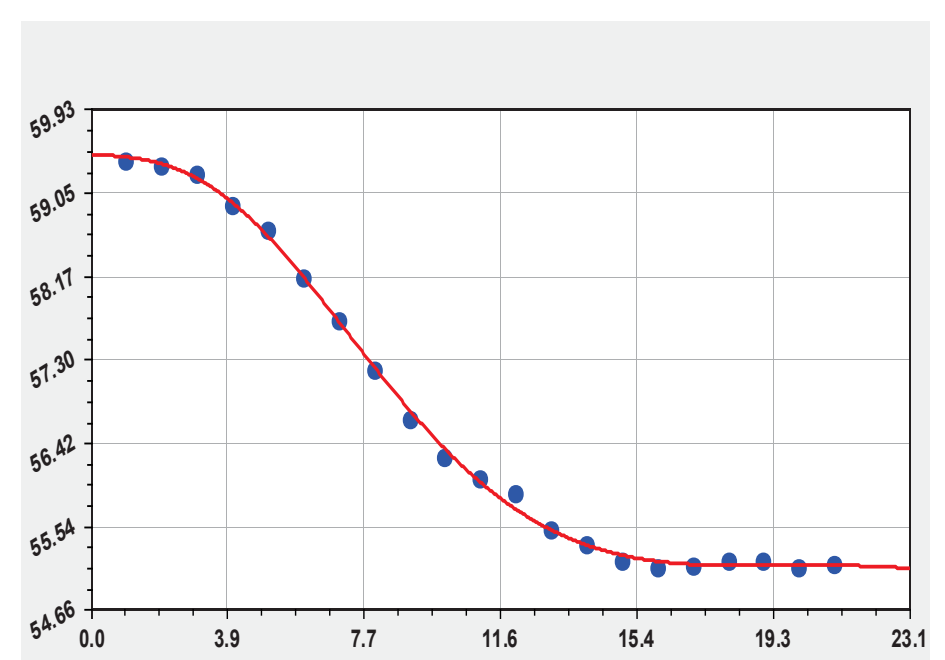

Рис. 2. Изменение доли в СХУ пашни

Первая составляющая всегда показывает естественную тенденцию, а вторая и последующие члены модели характеризуют, как правило, антропогенное воздействие.

В формуле (5) вторая составляющая, то есть влияние человеческого фактоpa, из-за отрицательного знака приобретает кризисный характер.

Доля в СХУ сенокосов и пастбищ. Здесь (рис. 3) получилась формула с положительным антропогенным влиянием

$$
\begin{gathered}
\alpha_{C I}=39,46844 \exp (-0,013364 t)+ \\
+0,385223 t^{1,40251} \exp (-0,040051 t) .
\end{gathered}
$$




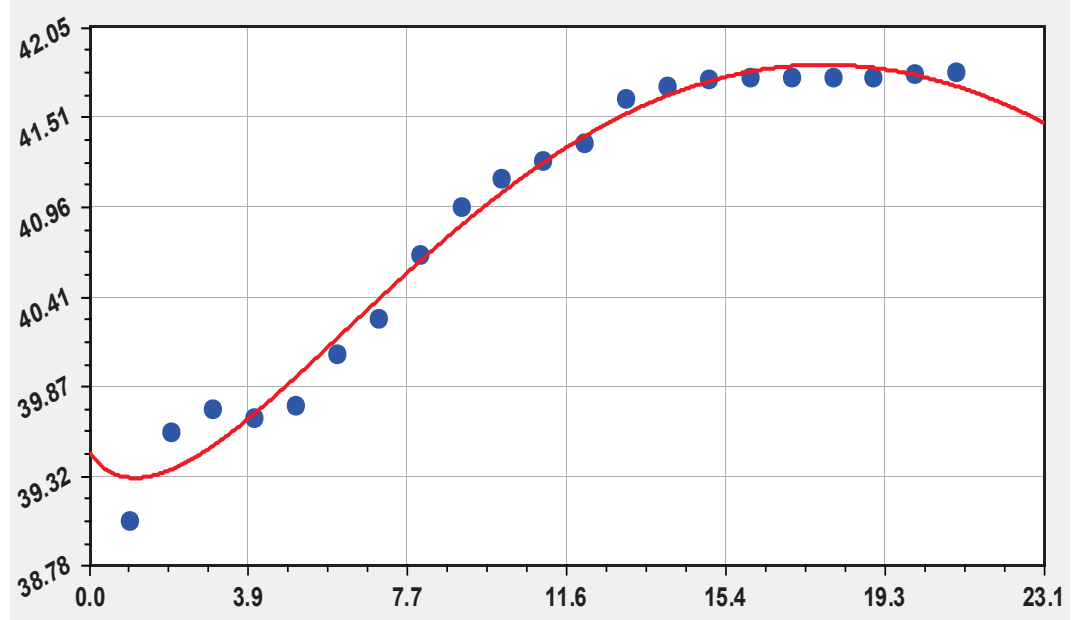

Рис. 3. Динамика доли в СХУ сенокосов и пастбищ

Таким образом, системный кризис положительно влияет на площадь под сенокосами и пастбищами. Мало осталось в России улучшенных сенокосов и высокопродуктивных по травяному покрову пастбищ.

Доля в СХУ залежи.

На рисунке 4 дан график динамики площади под залежи по формуле

$$
\begin{aligned}
& \alpha_{3}=1,00829 \exp \left(1,31070 t^{0,67142}\right)+ \\
& +0,043557 t^{1,82229} \exp \left(-0,014679 t^{1,56240}\right) .
\end{aligned}
$$

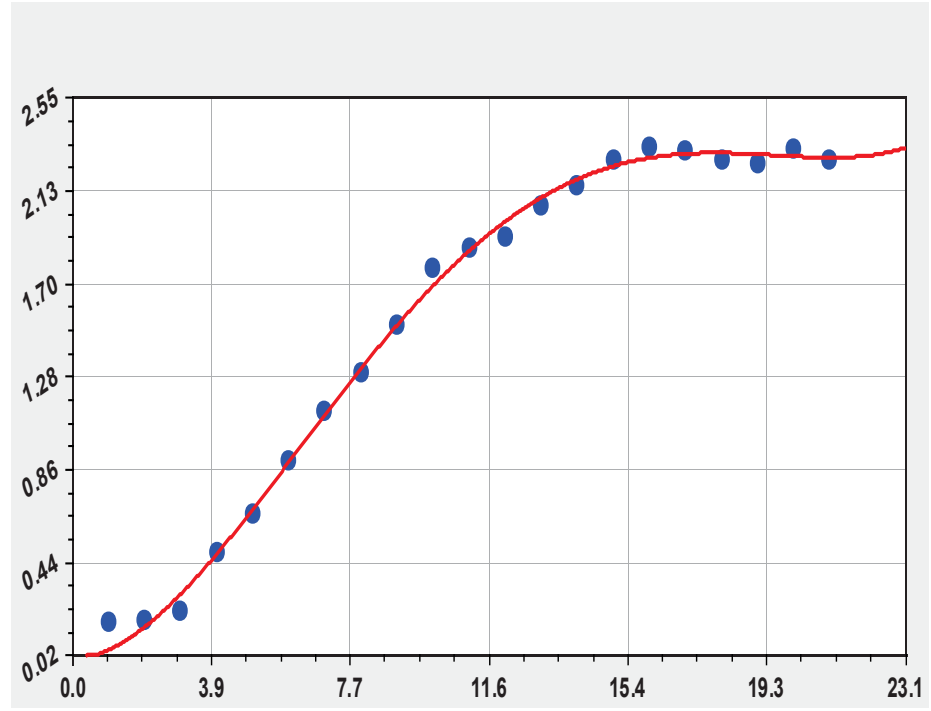

Рис. 4. Изменение доли в СХУ залежи

Залежи нарастают по экспоненциальному закону, при этом стрессовое возбуждение постепенно убывает и со временем будет только медленный рост площади залежи.

Bblводbl. Статистическое моделирование позволяет выявить высокоадекватные тренды динамики площади земель. Это позволяет надеяться, что, наконец-то, будут приниматься осознанные повороты в землепользовании, причем как по категориям земельного кадастра, так и по субъектам федерации.

\section{Литература:}

1. Арзамасцев А.Д., Мазуркин П.М., Максимец Н.В. Факторный анализ сельскохозяйственного производства. Йошкар-Ола: МарГТУ, 2009. 388 с. 
2. Мазуркин П.М. Геоэкология: Закономерности современного естествознания. Йошкар-Ола: МарГТУ, 2006. 336 с.

3. Мазуркин П.М. Коррелятивная вариация: учеб. пос. с грифомУМО РАЕ. Йошкар-Ола: Поволжский ГТУ, 2013. 120 с.

4. Мазуркин П.М., Ильменев Г.Н., Салахутдинов Ф.Н. Закономерности кадастровой оценки сельскохозяйственных угодий (на примере Республики Марий Эл). Йошкар-Ола: МарГТУ-ФГУП МарГипрозем, 2002. 66 с.

5. Мазуркин П.М., Касьянов Ю.В. Динамика управления земельным фондом субъекта федерации // Регистрация - кадастр. 2012. № 2. С.16-22.

6. Мазуркин П.М., Михайлова С.И. Биотехническая оценка пойменного луга. М.: Изд-во «Академия естествознания», 2009. 279 с.

7. Мазуркин П.М., Михайлова С.И. Модели кадастровой оценки сельхозугодий // АПК: Экономика и управление. 2009. № 8. С.76-82.

8. Мазуркин П. М., Михайлова С.И. Территориальное экологическое равновесие $=$ Territprial ecological balance: аналит. обзор; Учреждение Рос. акад. наук Гос. публич. науч.-техн. б-ка Сиб. отд-ния РАН. Новосибирск: ГПНТБ СО РАН, 2010. 430 с. (Сер. Экология. Вып. 94).

9. Мазуркин П.М., Фадеев А.Н. Закономерности распределения земельного фонда (на примере РМЭ). Йошкар-Ола: МарГТУ, 2006. 127 с.

10. Михайлова С.И., Мазуркин П.М. Ландшафтно-экологическая роль пойменного луга малых рек. Йошкар-Ола: МарГТУ, 2011. 154 с.

11. Государственный (национальный доклад) о состоянии и использовании земель в Российской Федерации в 2011 году. М.: Федеральная служба государственной регистрации, кадастра и картографии, 2012. 248 с.

\title{
ИНДУСТРИАЛЬНЫЕ ПАРКИ КАК ФОРМА ВОВЛЕЧЕНИЯ НЕИСПОЛЬЗОВАННЫХ ЗЕМЕЛЬ И ОБЪЕКТОВ НЕДВИЖИМО- СТИ В СОЗДАНИЕ РЕГИОНАЛЬНОЙ ИНВЕСТИЦИОННОЙ ИНФРАСТРУКТУРЫ (НА ПРИМЕРЕ ТВЕРСКОЙ ОБЛАСТИ)
}

\author{
Мамонов Г.Ю., \\ научный руководитель Баженова Т.Ю. \\ Тверской государственный университет, г. Тверь, Россия.
}

В конце 90-ых годов XX века индустриальные парки начали своё развитие в России. Новый импульс они получили, когда во второй половине 2000 -ых годов был введён федеральный закон № 116 «Об особых экономических зонах в Российской Федерации», ознаменовавший начало очередного этапа строительства инвестиционной инфраструктуры. Согласно исследованию, которое в 2011 году провела компания Ernst\&Young, в Российской Федерации насчитывается около 200 индустриальных парков разной степени готовности[9]. Около 60 из них либо уже были готовы к приёму резидентов, либо на их территории только началось строительство инфраструктуры. Самые ощутимые успехи по созданию индустриальных парков были замечены в республике Татарстан, Липецкой, Московской и Ленинградской областях, а так же в Калужской области, которая в 2010 году вышла на первое место по темпам прироста промышленной продукции и на второе по объёмам привлечённых прямых иностранных инвестиций [9]. Но отталкиваясь от данных, которые представила международная консалтинговая компания Knight Frank, можно сказать, что около поло- 